\title{
BMJ open Predictors of non-response in a UK-wide cohort study of children's accelerometer-determined physical activity using postal methods
}

To cite: Rich C, CortinaBorja M, Dezateux C, et al. Predictors of non-response in a UK-wide cohort study of children's accelerometerdetermined physical activity using postal methods. BMJ Open 2013;3:e002290. doi:10.1136/bmjopen-2012002290

- Prepublication history for this paper are available online. To view these files please visit the journal online (http://dx.doi.org/10.1136/ bmjopen-2012-002290)

Received 31 October 2012 Revised 5 February 2013 Accepted 6 February 2013

This final article is available for use under the terms of the Creative Commons Attribution Non-Commercial 2.0 Licence; see http://bmjopen.bmj.com

${ }^{1} \mathrm{MRC}$ Centre of Epidemiology for Child Health, UCL Institute of Child Health, London, UK

${ }^{2}$ Department of Quantitative Social Science, Institute of Education, University of London, London, UK

Correspondence to Carly Rich;

c.rich@ucl.ac.uk

\section{ABSTRACT}

Objectives: To investigate the biological, social, behavioural and environmental factors associated with non-consent, and non-return of reliable accelerometer data ( $\geq 2$ days lasting $\geq 10 \mathrm{~h} /$ day), in a UK-wide postal study of children's activity.

Design: Nationally representative prospective cohort study.

Setting: Children born across the UK, between 2000 and 2002.

Participants: 136817 to 8-year-old singleton children who were invited to wear an accelerometer on their right hip for 7 consecutive days. Consenting families were posted an Actigraph GT1M accelerometer and asked to return it by post.

Primary outcome measures: Study consent and reliable accelerometer data acquisition.

Results: Consent was obtained for 12872 (94.5\%) interviewed singletons, of whom 6497 (50.5\%) returned reliable accelerometer data. Consent was less likely for children with a limiting illness or disability, children who did not have people smoking near them, children who had access to a garden, and those who lived in Northern Ireland. From those who consented, reliable accelerometer data were less likely to be acquired from children who: were boys; overweight/ obese; of white, mixed or 'other' ethnicity; had an illness or disability limiting daily activity; whose mothers did not have a degree; who lived in rented accommodation; who exercised once a week or less; who had been breastfed; were from disadvantaged wards; had younger mothers or lone mothers; or were from households with just one, or more than three children.

Conclusions: Studies need to encourage consent and reliable data return in the wide range of groups we have identified to improve response and reduce non-response bias. Additional efforts targeted at such children should increase study consent and data acquisition while also reducing non-response bias. Adjustment must be made for missing data that account for missing data as a non-random event.

\section{ARTICLE SUMMARY}

Article focus

- This paper investigates the biological, social, behavioural and environmental factors associated with non-consent and non-return of reliable accelerometer data ( $\geq 2$ days lasting $\geq 10 \mathrm{~h} /$ day) in a UK-wide postal study of children's activity.

Key messages

- Consent was less likely for children with a limiting illness or disability, children who did not have people smoking near them or had access to a garden and children who lived in Northern Ireland.

- From those who consented, reliable data were less likely to be returned by boys, overweight/ obese children, those who were not white, mixed or 'other' ethnicity, younger mothers, mothers without a degree, families with only one parent, households with just 1 or more than 3 children, children who lived in rented accommodation, had been breastfed or had a limiting illness or disability and children from disadvantaged wards.

- Children who exercised less than twice a week according to the parent-proxy report of physical activity, were less likely to return reliable accelerometer data.

Strengths and limitations of this study

- This is the first large-scale accelerometer study using a postal distribution methodology to investigate the predictors of non-response associated with study non-consent and non-receipt of reliable data.

- A wide range of biological, social, behavioural and environmental factors are investigated as potential predictors of non-response. But our findings may not be directly applicable to different ages.

\section{BACKGROUND}

The development of accelerometers enables the frequency, intensity and duration of freeliving activity to be measured objectively in 
large-scale population studies. The majority of previous large scale accelerometer studies have demonstrated the use of the activity monitor to participants and distributed them in the context of a face-to-face meeting within a clinic ${ }^{1-3}$ or school setting. ${ }^{4-17}$ Although effective, the cost and time constraints of this data collection method can be substantial, particularly in large studies where subjects are geographically dispersed. The use of postal methods to distribute and return accelerometers can achieve higher population coverage than face-to-face administering and return, while also potentially reducing time and financial costs. Despite this, there are no large-scale accelerometer studies in UK children that have used this method.

Although non-response is a problem for nearly all large-scale studies, the use of a postal methodology may increase data loss and potentially introduce bias into study findings. Lack of face-to-face contact with researchers may reduce motivation for participation, or involve uncertainty for participants relating to the accelerometer wear or return protocol. There is also a dependence on external factors such as an efficient postal service and relying on subjects to return their accelerometers.

Few studies have examined predictors of consent in large-scale accelerometer studies in children. In those available, only the effects of gender ${ }^{17}$ and ethnicity ${ }^{5}$ have been investigated. No large-scale accelerometer studies using postal distribution methods have evaluated predictors of consent, and only one has evaluated differences between children who did and did not return reliable data. ${ }^{18}$ Gender, age and ethnic differences between children who did and did not provide reliable accelerometer data are well investigated in studies using face-to-face distribution methods, ${ }^{3} 510131618-22$ but the findings are inconsistent, possibly due to differences in study design, accelerometer protocol or study populations. Further research is needed to determine the factors associated with non-response in large-scale studies using a novel postal distribution methodology. This would enable researchers to minimise nonresponse, and also reduce the effect of bias through modification of analytical methods (eg, weighting analyses to account for non-response). Therefore, the aim of this study was to investigate the biological, social, behavioural and environmental predictors of nonresponse resulting from study non-consent and nonreturn of reliable accelerometer data in a UK-wide postal study of children's activity.

\section{METHODS}

\section{Study population}

The Millennium Cohort Study (MCS) is a UK-wide prospective study of the social, economic and health-related circumstances of British children born in the new century. ${ }^{23}$ All families who were claiming Child Benefit (all UK residents qualify for Child Benefit if they have children under 16 years) when their children were aged 9 months were eligible for sampling. A stratified clustered sampling design was employed to ensure an adequate representation of all four UK countries, disadvantaged areas and areas with high minority ethnic populations in England. The original cohort (MCS1) comprised 18818 children (18 295 singletons; response rate $72 \%$ ) whose parents were first interviewed at home when their child was aged 9 months. ${ }^{24}$ Three further home interviews have been completed, at ages 3, 5 and 7 years. At age 7 , accelerometers were used to measure children's activity. All children were invited to wear an accelerometer and written consent was obtained from the parents/guardians of those agreeing. Parents/guardians who gave consent were given an explanation on how their child should wear the accelerometer and were asked to demonstrate correctly putting a 'dummy' activity monitor on their child. Interviewers also explained how and when they should expect to receive their child's activity monitor, and how and when they should return the monitor.

\section{Accelerometer protocol}

Levels and patterns of physical activity (PA) were measured using the Actigraph GT1M uni-axial accelerometer (Actigraph, Pensacola, Florida). The Actigraph has been extensively validated in children against observational techniques, ${ }^{25}$ heart rate telemetry, ${ }^{26}$ indirect calorimetry $^{27}$ and energy expenditure measured by doubly labelled water. ${ }^{28} \mathrm{~A} 15 \mathrm{~s}$ sampling epoch was selected in order to optimise the ability to capture the sporadic nature of children's activity. ${ }^{29}$ Accelerometers were programmed using ActiLife Lifestyle Monitoring System software (V.3.2.11) to start collecting data at 05:00 2 days after posting. Accelerometers (attached to an elasticated belt) were posted together with a parent cover letter, an information leaflet, a timesheet, a letter for the child's class teacher and a prepaid envelope (for returning the accelerometer) to families via UK Royal Mail first class delivery. Families were asked to complete a timesheet to encourage accelerometer wear, recording the time the accelerometer was first put on in the morning and taken off at night, and any periods during the day when the accelerometer was not worn (including time spent swimming). Distribution occurred between May 2008 and August 2009. A free-phone telephone number was provided for families to call if they had any further questions. Families were sent translated versions of the documents if requested at the MCS home interview. Children were asked to start wearing their accelerometer the morning after they received it on their right hip for seven consecutive days during all waking hours, but were asked to remove it during all aquatic activities as these monitors are not waterproof. If children were unable to wear their accelerometer on the week requested, they were asked to return it so that it could be recharged and reprogrammed for a more convenient date. 
Parents/guardians were asked to return the accelerometer and completed timesheet as soon as possible after the monitoring period in the prepaid envelope. On return of the accelerometer, families were sent a certificate and a set of graphs summarising their child's weekly activity, together with a letter thanking them for their involvement. Three postal reminder letters were sent at weekly intervals to those not returning their accelerometer within 3 weeks after issue. The third reminder letter included an additional prepaid envelope. Further weekly reminders were issued by text, email or phone call depending on the contact details held. A final reminder letter offered families a $£ 10$ incentive gift voucher for the return of their accelerometer.

\section{Accelerometer data processing}

Accelerometer data were processed using the package pawacc $^{30}$ developed in the $\mathrm{R}$ software environment for statistical computing (V.2.15.0). ${ }^{31}$ Accelerometer non-wear was defined as any time period of consecutive zero-counts for a minimum of $20 \mathrm{~min}^{5}$ and counts $\geq 11715$ counts/min were excluded as these values were regarded as extreme. ${ }^{32}$ Children with a wear time period of $\geq 2$ days lasting $\geq 10 \mathrm{~h} /$ day were considered to provide reliable data. ${ }^{33}$ Full details on data processing are given in Geraci $e t a l^{4}$

\section{Statistical methods}

All analyses were conducted in STATA/SE V.11.0 (Stata Corporation, Texas, USA) and weighted using MCS survey and non-response weights to account for attrition between contacts and adjusted to allow for the clustered sample design. All singleton children that took part in the fourth sweep of the MCS (MCS4) interviews were included in the analyses $(n=13681)$. Twins and triplets were not included in the analyses because data were unintentionally not coded to allow the interview and accelerometer data for twins $(n=332)$ and triplets $(n=30)$ to be accurately linked. Sample sizes and weighted percentages were calculated for the total sample, and stratified for consenting and non-consenting children, and for children who did and did not return reliable accelerometer data, according to the potential predictor variables. Potential predictor variables are reported in table 1 , and were chosen based on prior research investigating non-response in previous large-scale accelerometer studies and the MCS4 interviews ${ }^{35} 36$ so that we could determine if the sample was biased according to factors typically associated with PA in children. ${ }^{24-26}$

All potential predictor variables were entered into unadjusted logistic regression models. p Values were obtained from adjusted Wald tests. Multicollinearity was investigated to determine which variables were to be included in the adjusted logistic regression models because several of the variables reported similar concepts. This was achieved by examining the bivariate correlations between all potential predictor variables, and calculating the variance inflation factors (VIF). The VIF is an index that measures how much the variance of an estimated regression coefficient is increased because of collinearity. ${ }^{38}$ VIF values were calculated using the formula $1 /\left(1-R^{2}\right)$ after regressing each potential predictor variable against all other variables (where $\mathrm{R}$ is the correlation coefficient between two variables); VIF values greater than 2.5 are often considered a matter of concern. ${ }^{38}$ Multicollinearity was evident between 'maternal occupation' $(\mathrm{VIF}=2.83)$ and 'whether the mother was in work or not' (VIF=2.54; correlation coefficient $=0.78$ ), and between 'government office region' $(\mathrm{VIF}=2.49)$ and 'country' (VIF=2.53; correlation coefficient $=0.77$ ). In each case, one of the pair of variables was removed from the model, one at a time, and the VIFs recalculated. The removal of 'mother in work or not' and 'government office region' reduced any signs of multicollinearity (ie, all variables had $\mathrm{VIF}<2.5$ ).

All the remaining variables were entered into two separate adjusted logistic regression models to determine the predictors of data loss resulting from study nonconsent and non-return of reliable data. $p$ Values were obtained from adjusted Wald tests to determine differences between the regression coefficients.

\section{RESULTS}

\section{Sample}

A total of 14043 children (13 681 singletons) took part in the fourth sweep of the MCS interviews (figure 1). Parents of 13219 (94.1\%) children (12 872 singletons) gave consent for their child to wear an accelerometer Accelerometers were sent to $12625(95.5 \%)$ consenting children (12 303 singletons); $29(0.2 \%)$ children were not sent an accelerometer because the fieldwork team were unable to send it during the requested time period, and full contact details of the remaining 565 $(4.3 \%)$ children were unavailable. We obtained reliable data ( $\geq 2$ days lasting $\geq 10 \mathrm{~h} /$ day) from $6675(50.5 \%$ ) consenting children (6497 singletons). A total of 7004 , 6326, 5910, 5153, 4002 and 2244 consenting children had $\geq 1, \geq 3, \geq 4, \geq 5, \geq 6$ and $\geq 7$ reliable days of data lasting at least $10 \mathrm{~h} /$ day.

\section{CONSENT}

\section{Unadjusted analyses}

Biological, social, behavioural and environmental factors were all associated with study consent (table 2). Pakistani/Bangladeshi children were almost half as likely to consent compared with white children. Several social factors were associated with non-consent including mothers not working, mothers without a degree (with the exception of those with no qualifications), households with only one child or an income of $£ 10400$ or less, households that spoke another language apart from English, and children who did not have people smoking near them. Children with a limiting illness or disability were half as likely to provide study consent compared with those without a limiting illness or disability. 
Table 1 Potential predictor variables used in analyses

\begin{tabular}{|c|c|c|}
\hline Factor & $\begin{array}{l}\text { Approximate age } \\
\text { of MCS child at } \\
\text { data collection }\end{array}$ & Level for analysis \\
\hline \multicolumn{3}{|l|}{ Biological } \\
\hline Child's gender & 7 years & Male; female \\
\hline Child's ethnicity* & 7 years & $\begin{array}{l}\text { White; mixed; Indian; Pakistani/Bangladeshi; black or } \\
\text { black British; other }\end{array}$ \\
\hline Child's body mass index (BMI) † & 7 years & Underweight/ normal weight; overweight/ obese \\
\hline \multicolumn{3}{|l|}{ Social } \\
\hline Mother's age at birth (years) & 9 months & $14-19 ; 20-29 ; 30-39 ; \geq 40$ \\
\hline Maternal current occupation $\ddagger$ & 7 years & $\begin{array}{l}\text { Managerial \& professional; intermediate; small } \\
\text { employers \& own account workers; lower supervisory \& } \\
\text { technical; semi- routine \& routine; non-employed }\end{array}$ \\
\hline Maternal highest academic qualification & 7 years & $\begin{array}{l}\text { Degree(s)/ post graduate diplomas; higher education/ } \\
\text { teaching qualifications/ diplomas; A/ AS/ S-levels; } \\
\text { O-levels/ GCSE grades A-C; GCSE grades D-G; other } \\
\text { academic qualifications; none of these }\end{array}$ \\
\hline Lone parent status & 7 years & Non-Ione parent; lone parent \\
\hline $\begin{array}{l}\text { Number of children in the household } \\
\text { (including the cohort child) }\end{array}$ & 7 years & $1 ; 2-3 ; \geq 4$ \\
\hline Main household language & 7 years & $\begin{array}{l}\text { English only; English and other language; non-English } \\
\text { speaking }\end{array}$ \\
\hline Whether anyone smokes near the child & 7 years & Yes; no \\
\hline Whether the mother is in work or not & 7 years & In work or on leave; not in work or leave \\
\hline Main housing tenure & 7 years & $\begin{array}{l}\text { Own outright, own mortgage/loan, part own/mortgage; } \\
\text { rent from local authority or housing association; rent } \\
\text { privately; other }\end{array}$ \\
\hline Type of accommodation & 7 years & $\begin{array}{l}\text { House or bungalow; flat or maisonette; studio, room, } \\
\text { bedsit, other }\end{array}$ \\
\hline Household income & 7 years & $\begin{array}{l}<£ 10400 ; £ 10400-20800 ; £ 20800-31200 ; \\
£ 31200-52000 ;>£ 52000\end{array}$ \\
\hline \multicolumn{3}{|l|}{ Behavioural } \\
\hline $\begin{array}{l}\text { Whether the child has any illnesses or } \\
\text { disabilities that limits activity }\end{array}$ & 7 years & Yes; no \\
\hline $\begin{array}{l}\text { Number of days a week the child } \\
\text { participates in sport or exercise: parent } \\
\text { report }\end{array}$ & 7 years & $\begin{array}{l}\geq 3 \text { days/week; } 2 \text { days/week; } 1 \text { day/week; less often/not } \\
\text { at all }\end{array}$ \\
\hline $\begin{array}{l}\text { Number of hours the child watches TV on } \\
\text { weekdays }\end{array}$ & 7 years & Less than an hour/not at all; $1-3 \mathrm{~h} ; 3-5 \mathrm{~h} ;>5 \mathrm{~h}$ \\
\hline Whether the child was ever breastfed & 9 months & Yes; no \\
\hline \multicolumn{3}{|l|}{ Environmental } \\
\hline Access to garden & 7 years & Yes; no \\
\hline Ward type (at time of sampling) $\S$ & 9 months & Advantaged; disadvantaged; ethnic \\
\hline Government office region & 7 years & $\begin{array}{l}\text { North East; North West; Yorkshire and the Humberside; } \\
\text { East Midlands; West Midlands; East of England; } \\
\text { London; South East; South West; Wales; Scotland; } \\
\text { Northern Ireland; Isle of Man/ Channel Islands }\end{array}$ \\
\hline UK country & 7 years & England; Wales; Scotland; Northern Ireland \\
\hline
\end{tabular}

Children who exercised less than once a week or had never been breastfed were also less likely to provide consent. Consent was also less likely for children from ethnic wards, or those who lived in Yorkshire and Humberside, London or Northern Ireland.

\section{Adjusted analyses}

After controlling for other predictor variables, consent remained significantly less likely for children who did not have people smoking near them and children with an illness or disability that limited daily activity (table 2). 


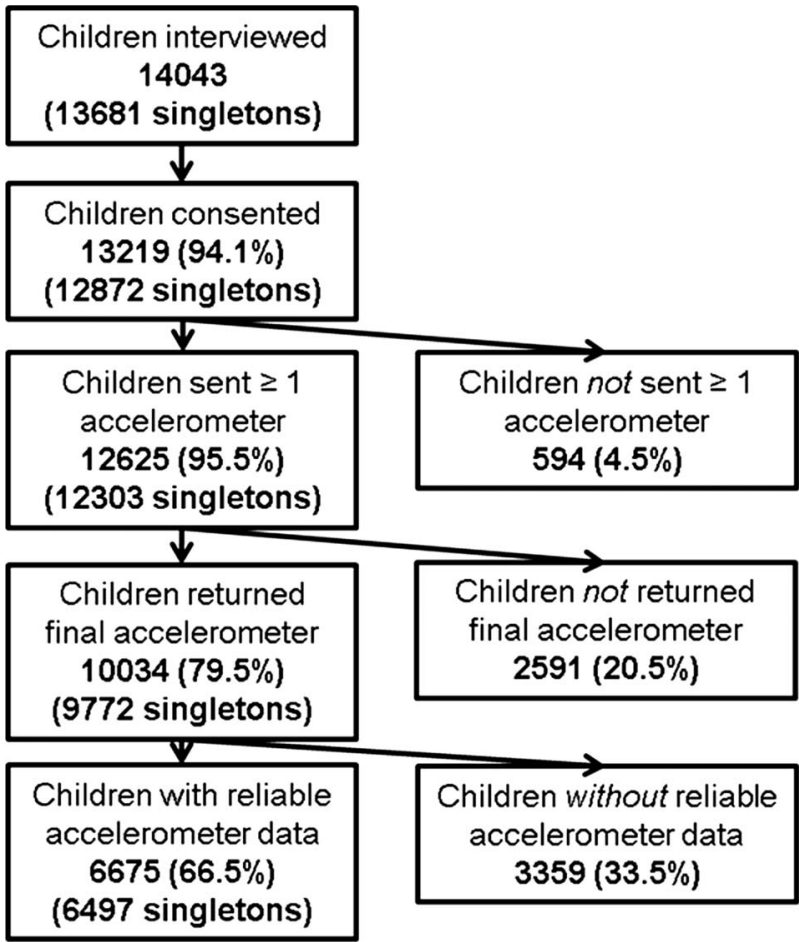

Figure 1 Summary of children in the Millennium Cohort accelerometer study.

Consent was also less likely for children who had access to a garden, and those who lived in Northern Ireland.

\section{RELIABLE DATA ACQUISITION Unadjusted analyses}

All variables in the unadjusted models were associated with reliable data acquisition except residential country (table 3). Within the sample who consented and were sent accelerometers, we were less likely to receive reliable data from boys, overweight/obese children and those who were not white or 'other' ethnicity. The social factors associated with non-return of reliable data included younger mothers $(<30$ at birth of cohort child), mothers not in managerial, professional, lower supervisory or technical occupations, or not educated to degree level, households with just one, or four or more children, or who spoke English and another language, children who had people smoking near them, or who lived in a flat or maisonette, and families who did not own their own home or had a household income of less than £31 200. Lone parents were half as likely to return reliable accelerometer data compared with two parent families. We were also less likely to acquire reliable accelerometer data from children with a limiting illness or disability, those who exercised 1 day a week or less, or watched TV for 3-5 h on weekdays or who had been breastfed. We were also less likely to acquire reliable data from children without access to a garden, children from disadvantaged or ethnic wards, and those who lived in North East or North West England, Yorkshire and
Humberside, West Midlands, London, Wales, Scotland or Northern Ireland.

\section{Adjusted analyses}

After controlling for other predictor variables, reliable accelerometer data acquisition was significantly less likely from boys, overweight/obese children and those who were not white, mixed or 'other' ethnicity (table 3). More social factors remained significantly associated with non-return of reliable data than with consent including younger mothers $(<30$ at birth of cohort child), mothers without a degree (excluding those with 'other' qualifications), lone parent families, households with just one, or four or more children and children that lived in any type of rented accommodation. We were also less likely to acquire reliable data from children with a limiting illness or disability, children who exercised once a week or less or had been breastfed and children from disadvantaged wards.

\section{DISCUSSION}

\section{Summary of findings}

In this nationally representative cohort of UK children, a high proportion of families $(94.1 \%$ of children interviewed; $n=13219$ ) agreed to take part in a study that used postal methods to distribute and return accelerometers in order to measure children's PA. The use of a postal methodology enabled the MCS to acquire a large volume of reliable accelerometer data $(n=6675 ; 51 \%$ of consenting children).

A number of different factors were associated with study non-consent and non-return of reliable accelerometer data in a nationally representative cohort of UK children (table 4). More differences were observed for the return of reliable data than in the consent to participate, quite likely to be due to the very high consent rate. In particular, a number of biological and social factors were related to non-return of reliable data that were not associated with non-consent. Social disadvantage was more apparent in children who did not return reliable data than in non-consenting children.

\section{Comparisons with existing research}

Few accelerometer-based studies of children's PA have investigated correlates of consent. ${ }^{5}{ }^{17}$ Van Sluijs et al ${ }^{17}$ and Owen et a $\tilde{l}$ investigated gender differences between children who consented to wearing an accelerometer in two large-scale studies. In contrast to our study, girls were more likely to consent than boys in the Sport, Physical activity and Eating behaviour: environmental Determinants in Young people (SPEEDY) ${ }^{17}$ study, whereas Owen et a $\bar{l}$ found no ethnic differences between consenting and non-consenting children participating in the Child Heart Health Study in England.

Only one large-scale study using postal methods to distribute and return accelerometers has investigated predictors of reliable data acquisition. ${ }^{18}$ Janz et $a l^{18}$ found 
Table 2 Weighted percentages and sample sizes for total singletons interviewed ( $n=13681)$, consenting $(n=12872)$ and non-consenting singletons ( $n=809)$, adjusted and unadjusted ORs $(95 \% \mathrm{Cl})$ and $\mathrm{p}$ values for predictors of consent

\begin{tabular}{|c|c|c|c|c|c|c|c|}
\hline & \multicolumn{3}{|l|}{ Weighted \% (n) } & \multicolumn{2}{|c|}{ Unadjusted regressions } & \multicolumn{2}{|l|}{ Adjusted regression } \\
\hline & Interviewed & Consenting & Non-consenting & OR (95\% CI) & $\overline{\text { p Value }}$ & OR (95\% Cl) & p Value \\
\hline All & $100.0(13681)$ & 94.5 (12872) & $5.5(809)$ & & & & \\
\hline \multicolumn{8}{|l|}{ Biological } \\
\hline \multicolumn{8}{|l|}{ Child's gender } \\
\hline Male & $51.4(6950)$ & $94.7(6541)$ & $5.3(409)$ & 1.07 (0.90 to 1.28$)$ & 0.442 & 1.10 (0.91 to 1.32$)$ & 0.318 \\
\hline Female & $48.6(6731)$ & $94.4(6331)$ & $5.6(400)$ & 1 & & 1 & \\
\hline \multicolumn{8}{|l|}{ Child's ethnicity } \\
\hline White & $85.5(11373)$ & $95.1(10745)$ & $4.9(628)$ & 1 & & 1 & \\
\hline Mixed & $3.2(367)$ & $91.9(345)$ & $8.1(22)$ & 0.59 (0.32 to 1.08$)$ & & 0.57 (0.30 to 1.10$)$ & 0.093 \\
\hline Indian & $1.9(339)$ & $91.8(316)$ & $8.2(23)$ & $0.58(0.35$ to 0.96$)$ & 0.089 & $0.91(0.45$ to 1.84$)$ & 0.793 \\
\hline Pakistani/Bangladeshi & 4.7 (869) & $92.1(794)$ & $7.9(75)$ & 0.61 (0.45 to 0.82$)$ & 0.001 & $1.06(0.67$ to 1.70$)$ & 0.779 \\
\hline Black or Black British & $3.2(446)$ & $92.8(411)$ & $7.2(35)$ & 0.67 (0.41 to 1.09$)$ & 0.103 & $0.64(0.36$ to 1.14$)$ & 0.126 \\
\hline Other & $1.4(186)$ & $92.4(173)$ & $7.6(13)$ & $0.63(0.32$ to 1.26$)$ & 0.190 & 1.06 (0.49 to 2.26$)$ & 0.884 \\
\hline \multicolumn{8}{|l|}{ Child's BMI } \\
\hline Under/normal weight & $79.9(10582)$ & $94.9(10011)$ & $5.1(571)$ & 1 & 0.313 & 1 & 0.802 \\
\hline Overweight/obese & $20.1(2759)$ & $94.4(2583)$ & $5.6(176)$ & $0.90(0.74$ to 1.10$)$ & & 0.97 (0.79 to 1.20$)$ & \\
\hline \multicolumn{8}{|l|}{ Social } \\
\hline \multicolumn{8}{|l|}{ Mother's age at birth (years) } \\
\hline $14-19$ & $8.5(1005)$ & $93.9(940)$ & $6.1(65)$ & $0.87(0.61$ to 1.26$)$ & 0.468 & $1.01(0.69$ to 1.48$)$ & 0.962 \\
\hline $20-29$ & $45.4(6103)$ & $94.7(5752)$ & $5.3(351)$ & $1.02(0.87$ to 1.19$)$ & 0.844 & $1.14(0.95$ to 1.36$)$ & 0.159 \\
\hline 30-39 & $43.4(6184)$ & $94.6(5817)$ & $5.4(367)$ & 1 & 0.215 & 1 & 0.983 \\
\hline$\geq 40$ & $2.7(389)$ & $93.0(363)$ & $7.0(26)$ & $0.75(0.48,1.18)$ & & $1.01(0.59$ to 1.73$)$ & \\
\hline \multicolumn{8}{|l|}{ Maternal occupation } \\
\hline Managerial and professional & 22.5 (3173) & 95.4 (3018) & $4.6(155)$ & 1 & & 1 & \\
\hline Intermediate & $12.9(1746)$ & $95.7(1666)$ & $4.3(80)$ & $1.08(0.73$ to 1.58$)$ & 0.707 & $1.21(0.80$ to 1.85$)$ & 0.371 \\
\hline Small employers and own account workers & $5.8(751)$ & $95.5(716)$ & $4.5(35)$ & $1.03(0.68$ to 1.55$)$ & 0.885 & $1.15(0.74$ to 1.77$)$ & 0.533 \\
\hline Lower supervisory and technical & $2.7(345)$ & $95.7(328)$ & $4.3(17)$ & $1.08(0.62$ to to 1.88$)$ & 0.797 & $1.26(0.67$ to to 2.38$)$ & 0.467 \\
\hline Semiroutine and routine & $18.1(2385)$ & $94.8(2248)$ & $5.2(137)$ & $0.88(0.64$ to 1.21$)$ & 0.433 & $1.03(0.73$ to 1.46$)$ & 0.847 \\
\hline Non-employed & $37.9(4993)$ & $93.3(4628)$ & $6.7(365)$ & $0.68(0.53$ to 0.88$)$ & 0.003 & $0.79(0.60$ to 1.07$)$ & 0.119 \\
\hline \multicolumn{8}{|l|}{ Maternal academic qualification } \\
\hline Degree(s)/postgraduate diplomas & $18.6(2756)$ & $95.5(2623)$ & $4.5(133)$ & 1 & & 1 & \\
\hline Higher education/teaching qualifications/diplomas & $11.4(1592)$ & $94.9(1512)$ & $5.1(80)$ & $0.88(0.63$ to 1.22$)$ & 0.441 & $0.81(0.56$ to 1.17$)$ & 0.265 \\
\hline A/AS/S-levels & $9.2(1299)$ & $94.9(1231)$ & $5.1(68)$ & $0.88(0.61$ to 1.25$)$ & 0.467 & $0.84(0.56$ to 1.26$)$ & 0.390 \\
\hline O-levels/GCSE grades A-C & $32.0(4219)$ & $94.6(3958)$ & $5.4(261)$ & $0.83(0.63$ to 1.10$)$ & 0.191 & $0.81(0.57$ to 1.13$)$ & 0.217 \\
\hline GCSE grades D-G & $11.0(1396)$ & $94.2(1308)$ & $5.8(88)$ & $0.77(0.52$ to 1.13$)$ & 0.182 & $0.72(0.47$ to 1.10$)$ & 0.129 \\
\hline Other academic qualifications & $2.5(358)$ & $93.3(335)$ & $6.7(23)$ & 0.66 (0.39 to 1.10$)$ & 0.109 & $0.73(0.43$ to 1.24$)$ & 0.247 \\
\hline None of these & $15.3(2057)$ & $93.3(1902)$ & $6.7(155)$ & $0.66(0.48$ to 0.91$)$ & 0.012 & $0.91(0.61$ to 1.35$)$ & 0.632 \\
\hline \multicolumn{8}{|l|}{ Lone parent status } \\
\hline Non-lone parent & $77.3(10785)$ & 94.7 (10157) & $5.3(628)$ & 1 & & 1 & \\
\hline Lone parent & $22.7(2896)$ & $94.0(2715)$ & $6.0(181)$ & $0.87(0.72$ to 1.05$)$ & 0.151 & $1.01(0.78$ to 1.29$)$ & 0.916 \\
\hline
\end{tabular}


Unadjusted regressions

Weighted \% (n)

Interviewed

Consenting

Non-consenting OR (95\% Cl)

\begin{tabular}{|c|c|c|c|c|c|c|}
\hline $13.3(1771)$ & 92.9 (1649) & $7.1(122)$ & $0.73(0.59$ to 0.90$)$ & 0.004 & 0.82 (0.64 to 1.05$)$ & 0.110 \\
\hline 72.9 (9886) & 94.8 (9325) & $5.3(561)$ & 1 & & 1 & \\
\hline 13.8 (2024) & $95.0(1898)$ & $5.0(126)$ & $1.05(0.82$ to 1.35$)$ & 0.695 & $1.30(0.99$ to 1.71$)$ & 0.062 \\
\hline 89.8 (11786) & 94.9 (11127) & $5.1(659)$ & 1 & & 1 & \\
\hline $9.6(1796)$ & $91.3(1656)$ & $8.7(140)$ & 0.56 (0.43 to 0.72$)$ & 0.000 & $0.68(0.46$ to 1.00$)$ & 0.052 \\
\hline $0.5(99)$ & 86.7 (89) & $13.3(10)$ & 0.35 (0.14 to 0.89$)$ & 0.027 & $0.45(0.16$ to 1.31$)$ & 0.145 \\
\hline 86.4 (11837) & 94.4 (11126) & $5.6(711)$ & 1 & & 1 & \\
\hline 13.6 (1759) & 95.8 (1672) & $4.2(87)$ & 1.37 (1.03 to 1.82$)$ & 0.031 & $\begin{array}{l}1.37(1.02 \text { to } 1.84) \\
\text { NA }\end{array}$ & $\begin{array}{l}0.037 \\
\text { NA }\end{array}$ \\
\hline $61.6(8511)$ & $95.2(8077)$ & $4.8(434)$ & 1 & 0.000 & & \\
\hline $38.4(5170)$ & $93.4(4795)$ & $6.6(375)$ & $0.71(0.60$ to 0.84$)$ & & & \\
\hline 63.1 (8996) & $94.6(8475)$ & $5.4(521)$ & 1 & 0.577 & 1 & 0.197 \\
\hline 24.9 (3092) & 94.3 (2900) & $5.8(192)$ & $0.93(0.72$ to 1.20$)$ & & $1.23(0.90$ to 1.70$)$ & \\
\hline $9.8(1177)$ & 95.8 (1118) & $4.2(59)$ & $1.30(0.94$ to 1.80$)$ & 0.111 & 1.49 (1.01 to 2.20$)$ & 0.045 \\
\hline $2.2(277)$ & 92.3 (258) & 7.7 (19) & $0.68(0.38$ to 1.21$)$ & 0.188 & 1.07 (0.59 to 1.94$)$ & 0.836 \\
\hline 89.9 (12436) & 94.6 (11708) & $5.4(728)$ & 1 & & 1 & \\
\hline 9.7 (1175) & 94.5 (1101) & $5.5(74)$ & 0.99 (0.70 to 1.41$)$ & 0.952 & 1.05 (0.65 to 1.68$)$ & 0.853 \\
\hline $0.4(49)$ & 99.7 (48) & $0.3(1)$ & 17.2 (2.78 to 106.5$)$ & 0.002 & NA & NA \\
\hline 13.1 (1733) & 92.6 (1603) & $7.5(130)$ & 0.56 (0.39 to 0.80$)$ & 0.001 & $0.73(0.46$ to 1.16$)$ & 0.185 \\
\hline 26.8 (3794) & $94.6(3561)$ & $5.4(233)$ & 0.78 (0.58 to 1.06$)$ & 0.113 & $1.02(0.71$ to 1.49$)$ & 0.896 \\
\hline 23.1 (3234) & 94.4 (3035) & $5.6(199)$ & $0.76(0.57$ to 1.00$)$ & 0.052 & 0.99 (0.72 to 1.37$)$ & 0.929 \\
\hline 24.9 (3359) & $95.2(3183)$ & $4.8(176)$ & 0.88 (0.64 to 1.22$)$ & 0.451 & $1.00(0.71$ to 1.42$)$ & 0.996 \\
\hline $12.2(1541)$ & $95.7(1474)$ & $4.3(67)$ & 1 & & & \\
\hline 93. 2 (12783) & 94.8 (12066) & $5.2(717)$ & 1 & & 1 & \\
\hline $6.8(898)$ & $90.8(806)$ & $9.2(92)$ & $0.54(0.41$ to 0.71$)$ & 0.000 & 0.65 (0.47 to 0.90$)$ & 0.010 \\
\hline 19.9 (2705) & 95.7 (2575) & $4.4(130)$ & 1 & & 1 & \\
\hline 20.8 (2829) & 95.7 (2693) & $4.3(136)$ & $1.02(0.76$ to 1.38$)$ & 0.899 & 1.12 (0.82 to 1.52$)$ & 0.486 \\
\hline 26.1 (3592) & 94.7 (3383) & $5.4(209)$ & 0.80 (0.61 to 1.07$)$ & 0.132 & $0.87(0.65$ to 1.19$)$ & 0.387 \\
\hline 33.2 (4485) & 93.1 (4161) & $6.9(324)$ & 0.62 (0.46 to 0.82$)$ & 0.001 & 0.77 (0.55 to 1.06$)$ & 0.110 \\
\hline 19.3 (2684) & 94.8 (2524) & $5.2(160)$ & 1 & & 1 & \\
\hline $64.8(8748)$ & 94.3 (8227) & $5.7(521)$ & $0.91(0.72$ to 1.14$)$ & 0.415 & 0.90 (0.70 to 1.16$)$ & 0.425 \\
\hline
\end{tabular}

Adjusted regression
Number of children in the household

2-3

$\geq 4$

Household language

English only

English and other

Non-English speaking

Whether anyone smokes near the child

No

Yes

Whether mother is in work or not

In work or leave

Not in work or leave

Main housing tenure

Own outright to full or part loan/mortgage

Rent from local authority or housing association

Rent privately

Other

Type of accommodation

House or bungalow

Flat or maisonette

Studio, room, bedsit, other

Household income

$<£ 10400$

$£ 10400-£ 20800$

$£ 20800-£ 31200$

$£ 31200-£ 52000$

$>£ 52000$

Behavioural

Disability or illness that limits activity No

Yes

Frequency of sport or exercise

3 or more days/week

2 days/week

1 day/week

Less often or not at all

Hours per weekday child watches TV

Less than an hour/not at all

$1-3 \mathrm{~h}$ 


\begin{tabular}{|c|c|c|c|c|c|c|c|}
\hline & \multicolumn{3}{|c|}{ Weighted \% (n) } & \multicolumn{2}{|c|}{ Unadjusted regressions } & \multicolumn{2}{|c|}{ Adjusted regression } \\
\hline & Interviewed & Consenting & Non-consenting & $\overline{\text { OR }(95 \% \mathrm{Cl})}$ & p Value & $\overline{\text { OR }(95 \% \mathrm{Cl})}$ & p Value \\
\hline $3-5$ hours & $11.1(1462)$ & $95.9(1388)$ & $4.1(74)$ & 1.30 (0.92 to 1.83$)$ & 0.136 & 1.37 (0.97 to 1.93$)$ & 0.073 \\
\hline$>5 \mathrm{~h}$ & $4.8(711)$ & $94.9(669)$ & $5.1(42)$ & $1.02(0.66$ to 1.56$)$ & 0.932 & $1.14(0.72$ to 1.81$)$ & 0.581 \\
\hline \multicolumn{8}{|l|}{ Child ever breastfed } \\
\hline No & $33.6(4394)$ & $93.6(4075)$ & $6.4(319)$ & 0.77 (0.64 to 0.93$)$ & 0.006 & 0.88 (0.72 to 1.09$)$ & 0.236 \\
\hline Yes & $66.5(9287)$ & $95.0(8797)$ & $5.0(490)$ & 1 & & 1 & \\
\hline \multicolumn{8}{|l|}{ Environmental } \\
\hline \multicolumn{8}{|l|}{ Access to garden } \\
\hline No & $7.4(905)$ & $95.6(857)$ & $4.4(48)$ & 1.27 (0.90 to 1.81$)$ & 0.178 & 1.70 (1.01 to 2.85$)$ & 0.045 \\
\hline Yes & $92.6(12755)$ & $94.5(12000)$ & $5.5(755)$ & 1 & & 1 & \\
\hline \multicolumn{8}{|l|}{ Ward type } \\
\hline Advantaged & $56.7(5693)$ & $95.1(5408)$ & $4.9(285)$ & 1 & & 1 & \\
\hline Disadvantaged & $37.0(6326)$ & $94.0(5924)$ & $6.0(402)$ & $0.80(0.62$ to 1.05$)$ & 0.103 & 0.89 (0.66 to 1.21$)$ & 0.466 \\
\hline Ethnic & $6.3(1662)$ & $92.2(1540)$ & $7.8(122)$ & 0.60 (0.46 to 0.80$)$ & 0.000 & 0.75 (0.48 to 1.17$)$ & 0.211 \\
\hline \multicolumn{8}{|l|}{ Government office region } \\
\hline North East & $3.6(395)$ & $93.4(368)$ & $6.6(27)$ & $0.42(0.16$ to 1.06$)$ & 0.065 & NA & NA \\
\hline North West & $10.8(1125)$ & $94.8(1063)$ & $5.2(62)$ & $0.54(0.28$ to 1.03$)$ & 0.062 & & \\
\hline Yorkshire and the Humberside & $8.9(1013)$ & $92.5(938)$ & $7.5(75)$ & 0.36 (0.18 to 0.73$)$ & 0.005 & & \\
\hline East Midlands & $7.3(734)$ & $95.3(705)$ & $4.7(29)$ & 0.60 (0.27 to 1.37$)$ & 0.226 & & \\
\hline West Midlands & $8.0(1009)$ & 95.7 (958) & $4.3(51)$ & 0.66 (0.32 to 1.34$)$ & 0.245 & & \\
\hline East of England & $9.3(971)$ & $96.7(935)$ & $3.3(36)$ & $0.86(0.41$ to 1.77$)$ & 0.674 & & \\
\hline London & $11.1(1403)$ & $93.7(1315)$ & $6.3(88)$ & 0.44 (0.23 to 0.85$)$ & 0.015 & & \\
\hline South East & $14.5(1360)$ & $94.6(1288)$ & $5.4(72)$ & $0.52(0.26$ to 1.03$)$ & 0.060 & & \\
\hline South West & $8.2(766)$ & $97.1(745)$ & $2.9(21)$ & 1 & 0.024 & & \\
\hline Wales & $5.1(1951)$ & $94.3(1844)$ & $5.7(107)$ & 0.49 (0.26 to 0.91$)$ & 0.019 & & \\
\hline Scotland & $9.3(1598)$ & $94.0(1499)$ & $6.0(99)$ & $0.46(0.24$ to 0.88$)$ & 0.000 & & \\
\hline Northern Ireland & $4.0(1354)$ & $89.3(1212)$ & $10.7(142)$ & 0.25 (0.13 to 0.46$)$ & & & \\
\hline Isle of Man/Channel Islands & $0.02(2)$ & $100(2)$ & $0(0)$ & NA & NA & & \\
\hline \multicolumn{8}{|l|}{ Country } \\
\hline England & $64.2(8786)$ & $95.0(8326)$ & $5.1(460)$ & 1 & & 1 & \\
\hline Wales & $14.2(1945)$ & $94.2(1838)$ & $5.8(107)$ & 0.87 (0.65 to 1.15$)$ & 0.313 & 0.97 (0.71 to 1.33$)$ & 0.859 \\
\hline Scotland & $11.6(1599)$ & $94.0(1500)$ & $6.0(99)$ & $0.83(0.60$ to 1.17$)$ & 0.287 & $0.73(0.51$ to 1.03$)$ & 0.077 \\
\hline Northern Ireland & $9.9(1351)$ & $89.1(1208)$ & $10.9(143)$ & $0.43(0.32$ to 0.59$)$ & 0.000 & $0.46(0.32$ to 0.65$)$ & 0.000 \\
\hline
\end{tabular}

Frequencies of missing data: ethnicity (101); BMI (340); occupation (288); academic (4); smoking (85); housing tenure (139), accommodation (21); income (20); sport (70); TV (76); garden (21). BMI, body mass index. 
Table 3 Weighted percentages and sample sizes for all singletons sent an accelerometer $(n=12303)$, singletons whom we did $(n=6497)$ and did not $(n=5806)$ acquire reliable accelerometer data, adjusted and unadjusted ORs $(95 \% \mathrm{Cl}$ ) and $\mathrm{p}$ values for predictors of reliable data acquisition

\begin{tabular}{|c|c|c|c|c|c|c|c|}
\hline & \multicolumn{3}{|l|}{ Weighted \% (n) } & \multicolumn{2}{|c|}{ Unadjusted regression } & \multicolumn{2}{|c|}{ Adjusted regression } \\
\hline & Sent & $\begin{array}{l}\text { Reliable data } \\
\text { acquired }\end{array}$ & $\begin{array}{l}\text { Reliable data } \\
\text { not acquired }\end{array}$ & OR (95\% Cl) & p Value & OR (95\% Cl) & p Value \\
\hline All & $100.0(12303)$ & 52.7 (6497) & $47.3(5806)$ & & & & \\
\hline \multicolumn{8}{|l|}{ Biological } \\
\hline \multicolumn{8}{|l|}{ Child's gender } \\
\hline Male & $51.2(6233)$ & $50.8(3176)$ & $49.2(3057)$ & $0.86(0.78$ to 0.95$)$ & 0.002 & $0.81(0.74$ to 0.90$)$ & 0.000 \\
\hline Female & $48.8(6070)$ & $54.6(3321)$ & $45.4(2749)$ & 1 & & 1 & \\
\hline \multicolumn{8}{|l|}{ Child's ethnicity } \\
\hline White & $86.2(10310)$ & $54.8(5685)$ & $45.2(4625)$ & 1 & & 1 & 0.206 \\
\hline Mixed & 3.1 (329) & $47.7(167)$ & $52.3(162)$ & 0.75 (0.57 to 0.99$)$ & 0.045 & 0.84 (0.63 to 1.10$)$ & 0.004 \\
\hline Indian & $1.9(305)$ & 42.7 (139) & $57.4(166)$ & 0.61 (0.44 to 0.85$)$ & 0.003 & 0.50 (0.31 to 1.10$)$ & 0.001 \\
\hline Pakistani/Bangladeshi & $4.4(726)$ & $32.2(243)$ & $67.8(483)$ & $0.39(0.31$ to 0.49$)$ & 0.000 & $0.50(0.34$ to 0.70$)$ & 0.002 \\
\hline Black or Black British & $3.1(386)$ & $36.6(151)$ & $63.5(235)$ & 0.47 (0.34 to 0.65$)$ & 0.000 & $0.58(0.41$ to 0.83$)$ & 0.838 \\
\hline Other & $1.4(165)$ & $53.1(80)$ & $36.6(85)$ & 0.93 (0.66 to 1.29$)$ & 0.688 & 0.95 (0.59 to 1.36$)$ & \\
\hline \multicolumn{8}{|l|}{ Child's BMI } \\
\hline Under/normal weight & $80.1(9671)$ & $54.5(5315)$ & 45.5 (4356) & 1 & & 1 & \\
\hline Overweight/obese & $19.9(2483)$ & $45.5(1114)$ & $54.6(1369)$ & 0.69 (0.63 to 0.77$)$ & 0.000 & 0.73 (0.66 to 0.82$)$ & 0.000 \\
\hline \multicolumn{8}{|l|}{ Social } \\
\hline \multicolumn{8}{|l|}{ Mothers age at birth (years) } \\
\hline $14-19$ & $8.4(895)$ & $31.8(283)$ & $68.2(612)$ & $0.30(0.25$ to 0.36$)$ & 0.000 & $0.52(0.42$ to 0.64$)$ & 0.000 \\
\hline 20-29 & $45.3(5486)$ & $48.5(2660)$ & $51.5(2826)$ & 0.61 (0.56 to 0.68$)$ & 0.000 & 0.78 (0.71 to 0.85$)$ & 0.000 \\
\hline 30-39 & 43.7 (5578) & $60.6(3346)$ & 39.4 (2232) & 1 & & $1+1$ & \\
\hline$>40$ & $2.6(344)$ & $59.3(208)$ & $40.7(136)$ & 0.95 (0.74 to 1.21$)$ & 0.654 & $1.21(0.92$ to 1.60$)$ & 0.171 \\
\hline \multicolumn{8}{|l|}{ Maternal occupation } \\
\hline Managerial and professional & $22.9(2907)$ & $62.5(1806)$ & 37.5 (1101) & 1 & & 1 & \\
\hline Intermediate & $13.3(1621)$ & $56.4(922)$ & $43.6(699)$ & $0.78(0.67$ to 0.90$)$ & 0.001 & 0.97 (0.83 to 1.14$)$ & 0.728 \\
\hline $\begin{array}{l}\text { Small employers and own account } \\
\text { workers }\end{array}$ & $6.0(695)$ & $55.9(387)$ & $44.1(308)$ & 0.76 (0.64 to 0.91$)$ & 0.002 & $0.89(0.74 .1 .08)$ & 0.236 \\
\hline Lower supervisory and Technical & $2.8(318)$ & $54.3(177)$ & $45.7(141)$ & 0.71 (0.54 to 0.94$)$ & 0.015 & $1.13(0.84$ to 1.52$)$ & 0.413 \\
\hline Semiroutine and routine & $18.1(2140)$ & $51.2(1104)$ & $48.8(1036)$ & $0.63(0.56$ to 0.71$)$ & 0.000 & $1.01(0.88$ to 1.17$)$ & 0.838 \\
\hline Non-employed & $37.0(4377)$ & $45.6(1978)$ & 54.4 (2299) & $0.50(0.45$ to 0.56$)$ & 0.000 & 1.03 (0.90 to 1.18$)$ & 0.691 \\
\hline \multicolumn{8}{|l|}{ Maternal academic qualification } \\
\hline Degree(s)/postgraduate diplomas & $19.0(2525)$ & $67.1(1661)$ & $32.9(864)$ & 1 & & 1 & \\
\hline $\begin{array}{l}\text { Higher education/teaching } \\
\text { qualifications/diplomas }\end{array}$ & $11.7(1473)$ & $58.4(854)$ & $41.6(619)$ & 0.69 (0.59 to 0.80$)$ & 0.000 & $0.82(0.69$ to 0.96$)$ & 0.015 \\
\hline A/AS/S-levels & $9.4(1187)$ & $56.8(682)$ & $43.2(505)$ & 0.64 (0.54 to 0.77$)$ & 0.000 & $0.78(0.65$ to 0.93$)$ & 0.007 \\
\hline O-levels/GCSE grades A-C & $32.1(3787)$ & $51.4(1940)$ & $48.6(1847)$ & $0.52(0.46$ to 0.59$)$ & 0.000 & $0.70(0.61$ to 0.82$)$ & 0.000 \\
\hline GCSE grades D-G & $10.8(1242)$ & $46.4(571)$ & $53.6(671)$ & $0.42(0.36$ to 0.50$)$ & 0.000 & $0.71(0.58$ to 0.86$)$ & 0.000 \\
\hline Other academic qualifications & $2.3(311)$ & $44.7(132)$ & $55.3(179)$ & $0.40(0.29$ to 0.54$)$ & 0.000 & $0.76(0.54$ to 1.06$)$ & 0.102 \\
\hline None of these & $14.8(1776)$ & 35.7 (657) & $64.3(1119)$ & 0.27 (0.23 to 0.32$)$ & 0.000 & $0.56(0.47$ to 0.67$)$ & 0.000 \\
\hline
\end{tabular}


Table 3 Continued

\begin{tabular}{|c|c|c|c|c|c|c|c|}
\hline & \multicolumn{3}{|c|}{ Weighted \% (n) } & \multicolumn{2}{|c|}{ Unadjusted regression } & \multicolumn{2}{|c|}{ Adjusted regression } \\
\hline & Sent & $\begin{array}{l}\text { Reliable data } \\
\text { acquired }\end{array}$ & $\begin{array}{l}\text { Reliable data } \\
\text { not acquired }\end{array}$ & OR (95\% Cl) & p Value & OR (95\% Cl) & p Value \\
\hline 1 day/week & $26.0(3227)$ & $51.5(1662)$ & $48.5(1565)$ & 0.63 (0.56 to 0.72$)$ & 0.000 & $0.80(0.70$ to 0.91$)$ & 0.001 \\
\hline Less often or not at all & 32.4 (3955) & $41.9(1708)$ & 58.1 (2247) & 0.43 (0.38 to 0.49$)$ & 0.000 & 0.73 (0.64 to 0.83 ) & 0.000 \\
\hline Less than an hour/not at all & $19.2(2411)$ & $54.8(1337)$ & $45.2(1074)$ & 1 & & 1 & \\
\hline $1-3 \mathrm{~h}$ & $64.8(7891)$ & $53.3(4205)$ & $46.7(3686)$ & 0.94 (0.84 to 1.06$)$ & 0.316 & 1.09 (0.96 to 1.24$)$ & 0.170 \\
\hline $3-5 \mathrm{~h}$ & $11.3(1330)$ & $47.3(640)$ & $52.7(690)$ & 0.74 (0.62 to 0.88$)$ & 0.001 & 1.07 (0.89 to 1.28$)$ & 0.490 \\
\hline \multicolumn{8}{|l|}{ Child ever breastfed } \\
\hline Yes & $66.9(8425)$ & $43.5(1691)$ & $56.5(2187)$ & 0.58 (0.52 to 0.64$)$ & 0.000 & 0.81 (0.74 to 0.91$)$ & 0.000 \\
\hline No & 33.1 (3878) & $57.2(4806)$ & $42.8(3619)$ & 1 & & 1 & \\
\hline \multicolumn{8}{|l|}{ Environmental } \\
\hline \multicolumn{8}{|l|}{ Access to garden } \\
\hline No & $7.4(803)$ & $37.7(315)$ & $62.3(488)$ & 0.52 (0.42 to 0.63$)$ & 0.000 & 1.00 (0.75 to 1.22$)$ & 0.982 \\
\hline Yes & $92.6(11486)$ & $53.9(6179)$ & $46.1(5307)$ & 1 & & 1 & \\
\hline \multicolumn{8}{|l|}{ Ward type } \\
\hline North West & $10.9(1025)$ & $48.7(466)$ & $51.3(559)$ & 0.48 (0.36 to 0.66$)$ & 0.000 & & \\
\hline Yorkshire and the Humberside & $8.6(892)$ & $54.0(438)$ & $46.0(454)$ & $0.60(0.43$ to 0.84$)$ & 0.003 & & \\
\hline East midlands & $7.4(682)$ & $61.3(400)$ & $38.7(282)$ & $0.84(0.60$ to 1.19$)$ & 0.338 & & \\
\hline West Midlands & $8.2(913)$ & $53.5(451)$ & $46.5(462)$ & 0.60 (0.43 to 0.83$)$ & 0.002 & & \\
\hline East of England & $9.6(901)$ & $62.3(534)$ & $37.7(367)$ & $0.87(0.66 .1 .16)$ & 0.346 & & \\
\hline London & $10.8(1230)$ & $48.7(577)$ & $51.3(653)$ & $0.52(0.38$ to 0.70$)$ & 0.000 & & \\
\hline South East & $14.6(1233)$ & $58.9(713)$ & $41.1(520)$ & 0.78 (0.59 to 1.02$)$ & 0.068 & & \\
\hline South West & $8.3(709)$ & $64.4(448)$ & $35.6(261)$ & 1 & & & \\
\hline Wales & $5.0(1755)$ & $56.0(899)$ & $44.0(856)$ & 0.65 (0.50 to 0.85$)$ & 0.002 & & \\
\hline Scotland & $9.1(1421)$ & $54.8(761)$ & $45.2(660)$ & 0.64 (0.48 to 0.86$)$ & 0.003 & & \\
\hline Northern Ireland & $4.0(1201)$ & $54.9(636)$ & $45.1(565)$ & 0.68 (0.52 to 0.91$)$ & 0.010 & & \\
\hline Isle of Man/Channel Islands & $0.02(2)$ & $61.4(1)$ & $38.6(1)$ & 0.96 (0.06 to 15.02$)$ & 0.978 & & \\
\hline \multicolumn{8}{|l|}{ Country } \\
\hline England & 64.7 (7936) & $53.0(4204)$ & 47.1 (3732) & 1 & & 1 & \\
\hline Wales & $14.1(1748)$ & $51.2(898)$ & $48.8(850)$ & 0.93 (0.81 to 1.07$)$ & 0.304 & 0.96 (0.84 to 1.09$)$ & 0.521 \\
\hline
\end{tabular}

Frequencies of missing data: ethnicity (82); BMI (149); occupation (245); academic (2); smoking (46); housing tenure (83), accommodation (14); income (11); sport (36); TV (39); garden (14). BMI, body mass index. 
Table 4 Predictors of study non-consent and non-receipt of reliable accelerometer data in the Millennium Cohort accelerometer Study

\begin{tabular}{ll}
\hline Study non-consent & Non-return of reliable accelerometer data \\
\hline & Biological \\
& Boys \\
& Non-white, mixed or 'other' ethnicity children \\
& Social \\
& Younger mothers (<30 at birth of cohort child) \\
Behavioural & Mothers without a degree \\
Children with a limiting illness or disability & Lone parents \\
Children who did not have people smoking near & Children who lived in rented accommodation \\
them & Behavioural \\
Environmental & Children with a limiting illness or disability \\
Children who had access to a garden & Children who exercised once a week or less \\
Children who lived in Northern Ireland & Children who had been breastfed \\
\end{tabular}

no differences between boys and girls according to the number of days of reliable data they provided. Other large-scale studies using face-to-face distribution methods have investigated potential predictors of reliable data acquisition using a range of factors, but the findings are inconsistent. In four studies, younger children were more likely to provide reliable accelerometer data than older children, ${ }^{320-22}$ whereas another three found no age differences. ${ }^{10} 16{ }^{19}$ In agreement with our study, boys were less likely to provide reliable data than girls in the Avon Longitudinal Study of Parents and Children (ALSPAC) ${ }^{20}$ and the UK Children's Health and Activity Monitoring Program. ${ }^{13}$ In contrast, the National Health and Nutrition Examination Survey ${ }^{3}$ and the SPEEDY study ${ }^{17}$ reported that girls were less likely to return reliable data than boys: no gender differences in reliable data acquisition were reported in several other studies. ${ }^{101921}$ In contrast to our study, no ethnic differences according to reliable data acquisition were reported by previous studies. ${ }^{5} 131921$ The majority of previous studies report that weight status was not related to reliable data acquisition. ${ }^{10131639}$ However, in agreement with our study, overweight children were less likely to return reliable data than non-overweight children in the ALSPAC, ${ }^{20}$ whereas overweight children were more likely to provide reliable data than non-overweight children in Project EAST $^{19}$

Few studies have investigated behavioural predictors of reliable data acquisition. ${ }^{101621}$ No previous studies have reliably investigated whether PA predicts non-response. However, the Physical Exercise and Appetite in Children Study reported that they were more likely to acquire reliable data from physically active children than those who were less active. ${ }^{10}$ In contrast, Sirard et $a l^{21}$ reported that PA levels did not predict whether children returned reliable accelerometer data. Both studies compared the PA levels of children who did and did not return reliable data; however, PA is not reliably estimated in children without reliable data. Only studies with an alternative measure of activity can accurately estimate PA differences in non-response. Few studies have investigated social and environmental factors as potential predictors of reliable data acquisition, although studies have looked at socioeconomic status, ${ }^{10}$ child deprivation, ${ }^{13}$ local and area independent mobility, ${ }^{16}$ child $^{19}$ and parental ${ }^{17}$ education and free school meal status. ${ }^{22}$

\section{Strengths and limitations}

The MCS4 is the first large-scale longitudinal cohort study to objectively measure PA in a socially and ethnically diverse population of children from all four UK countries. This is also the first large-scale accelerometer study using a postal distribution methodology to investigate the predictors of non-response associated with study non-consent and non-return of reliable data. The MCS provided a range of biological, social, behavioural and environmental information on children, their families and their environment, which enabled us to simultaneously examine a broad range of potential predictors. As this is a contemporary cohort, the findings of this study are applicable to the lives of young children now. Furthermore, we have used a robust accelerometer wear time threshold to define children with reliable data. ${ }^{33}$

However, our findings may not be applicable to different ages. PA levels vary according to age, and children's $\mathrm{PA}$ is very different from adult's PA in many respects; ${ }^{3}$ it is therefore unlikely that without further research the findings of this study can be applied to adult populations. Age has also been shown to be related to the return of reliable accelerometer data in several studies. $^{3}{ }^{20-22}$ In addition, although the UK country of residence did not predict non-response in our study, our findings may differ in other studies involving samples of children living in non-UK countries. 
Many of the predictor variables in this study were based on parent-report measures, and therefore recall bias may have influenced the information collected. For example, maternal reports of smoking near the child at the age 7 sweep may have been underreported, although any underestimate in this is likely to lead to an underestimate of the effect. ${ }^{40}$ However, the information collected within the MCS using parent-report methods has been shown to be valid and reliable. ${ }^{41} 42$ Non-consent for children who did not have people smoking near them may reflect highly protective parents. A small number of the MCS children had missing data for the predictor variables. Since the MCS has a large sample size, imputing data for these missing variables would only increase the sample size by a small proportion. Several factors that were not investigated within this study may also influence non-response, for example, who the cohort children were interviewed by, whether they were sent, or tried to return an accelerometer during a postal strike, or which reminder methods were sent to the family to encourage return of the accelerometer.

\section{Recommendations for study practice and further research}

This study has reported the biological, social, behavioural and environmental factors associated with nonresponse in a PA study using postal methods to distribute and return accelerometers. Researchers should be aware of these factors and recognise potential bias occurring as a result of this methodology so that future studies can implement strategies to reduce the threat of data loss. For example, we found that the language spoken by the cohort families at MCS4 did not influence consent. This may be because non-English speaking families were offered translated versions of all study documents, and a translator was made available at the study interview. However, consent was less likely from children living in Northern Ireland; this may be because a different fieldwork agency conducted the home interviews in Northern Ireland than in England, Wales and Scotland. Considerable efforts are required by researchers and parents to encourage boys, non-white and overweight/ obese children to wear and return their accelerometer as requested so that we can acquire reliable data from these populations. Lone parents and families with a large number of children may not have returned their child's accelerometer because they forgot, or did not have the time to do so. Therefore, it is crucial that studies issue timely reminders throughout fieldwork, and in particular, to these populations. Caution should also be taken if sampling children with an illness or disability that limits daily activity as non-response was very high among these children and may therefore bias study findings.

Further research should be aimed at investigating whether the predictors of non-response identified in this study also predict non-response in other large-scale accelerometer studies across different age groups and countries, and in studies using different accelerometer distribution and return methods. If studies are unable to increase response in the populations identified in our study, then researchers need to be aware of their influence on the validity of findings, and control for these factors in associated analyses. An important finding was that children who were reported to exercise once a week or less were less likely to return reliable data. As a result, study findings may be biased as inferences about the PA levels of the population that are based on the observed sample may not be the same as those based on the target sample. However, the PA predictor variable was based on the parent-proxy report of their child's usual weekly frequency of sport or any other PA. The limitations associated with parent-proxy reports of children's PA have been well defined. ${ }^{43}$ Although it is beyond the scope of the study, several statistical methods to deal with missing data have been developed and their performance in reducing estimation bias depends on the quality of the models that underpin them. ${ }^{44}$ Current work is being undertaken to develop response propensity weighting adjustments in the MCS4 accelerometer study.

\section{CONCLUSION}

Researchers should be aware of factors associated with non-response in a large-scale accelerometer study that uses postal distribution and return methods so that future studies can implement strategies to reduce the threat of data loss. Accelerometer studies in children who use our postal methodology need to encourage data return from boys, overweight/obese and non-white children, mothers who are young or who have few qualifications, families with only one parent or a large number of children, children who exercise less than twice a week and children living in various forms of disadvantaged circumstances. If studies are unable to increase response in these sections of the population, then researchers should weight analyses to account for non-response.

Acknowledgements The work of the accelerometer data collection team (Jane Ahn, Florence Kinnafick and Richard Pulsford) is gratefully acknowledged, as is the co-operation of the participating MCS families.

Contributors CR, LJG, MCB and CD were responsible for the conception and design of the study. CR carried out the statistical analyses and drafted the manuscript. MG generated and produced the accelerometer data processing software. MCB, FS and CR also made substantial contributions towards accelerometer data processing. $\mathrm{HJ}$, as director of the MCS, worked with $\mathrm{CD}$ to raise the funding from the Wellcome Trust, and oversaw the CLS collaboration in the project. LC made substantial contributions towards the accelerometer fieldwork protocol. All authors contributed towards revising the manuscript and have approved the final manuscript.

Funding The MCS4 accelerometer study was funded by the Wellcome Trust (grant 084686/Z/08/A). The MRC Centre of Epidemiology for Child Health is supported by funds from the UK Medical Research Council (grant G0400546). Research at the UCL Institute of Child Health \& Great Ormond Street Hospital for Children receives a proportion of funding from the Department of Health's National Institute for Health Research Biomedical Research Centres funding scheme. The Millennium Cohort Study is funded by grants to the Centre for 
Longitudinal Studies at the Institute of Education from the Economic and Social Research Council and a consortium of government departments.

Competing interests None.

Ethics approval Northern and Yorkshire Research Ethics Committee (REC number: 07/MRE03/32).

Provenance and peer review Not commissioned; externally peer reviewed.

Data sharing statement The MCS data for surveys 1-4 are currently available via the Economic and Social Data Service; the MCS accelerometer data will be available at the beginning of 2013.

\section{REFERENCES}

1. Riddoch CJ, Mattocks C, Deere K, et al. Objective measurement of levels and patterns of physical activity. Arch Dis Child 2007;92:963-9.

2. Taylor RW, Murdoch L, Carter P, et al. Longitudinal study of physica activity and inactivity in preschoolers: the FLAME study. Med Sci Sports Exerc 2009;41:96-102.

3. Troiano RP, Berrigan D, Dodd KW, et al. Physical activity in the United States measured by accelerometer. Med Sci Sports Exerc 2008;40:181-8.

4. Riddoch CJ, Bo AL, Wedderkopp N, et al. Physical activity levels and patterns of 9- and 15-yr-old European children. Med Sci Sports Exerc 2004;36:86-92.

5. Owen CG, Nightingale CM, Rudnicka AR, et al. Ethnic and gender differences in physical activity levels among 9-10-year-old children of white European, South Asian and African-Caribbean origin: the Child Heart Health Study in England (CHASE Study). Int $J$ Epidemiol 2009;38:1082-93.

6. Pfeiffer KA, Dowda M, Mclver KL, et al. Factors related to objectively measured physical activity in preschool children. Pediatr Exerc Sci 2009;21:196-208

7. Timperio A, Crawford D, Telford A, et al. Perceptions about the local neighborhood and walking and cycling among children. Prev Med 2004;38:39-47.

8. Vale $\mathrm{S}$, Silva $\mathrm{P}$, Santos $\mathrm{R}$, et al. Compliance with physical activity guidelines in preschool children. J Sports Sci 2010;28:603-8.

9. Eiberg S, Hasselstrom H, Gronfeldt V, et al. Maximum oxygen uptake and objectively measured physical activity in Danish children 6-7 years of age: the Copenhagen school child intervention study. Br J Sports Med 2005;39:725-30.

10. Purslow LR, Hill C, Saxton J, et al. Differences in physical activity and sedentary time in relation to weight in 8-9 year old children. Int $J$ Behav Nutr Phys Act 2008;5:67.

11. Brockman $R$, Jago $R$, Fox KR. The contribution of active play to the physical activity of primary school children. Prev Med 2010;51:144-7.

12. Stevens J, Suchindran C, Ring K, et al. Physical activity as a predictor of body composition in American Indian children. Obes Res 2004;12:1974-80.

13. Gidlow CJ, Cochrane T, Davey R, et al. In-school and out-of-school physical activity in primary and secondary school children. J Sports Sci 2008;26:1411-19.

14. Trost SG, Pate RR, Freedson PS, et al. Using objective physical activity measures with youth: how many days of monitoring are needed? Med Sci Sports Exerc 2000;32:426-31.

15. Thompson AM, Campagna PD, Durant M, et al. Are overweight students in Grades 3, 7, and 11 less physically active than their healthy weight counterparts? Int J Pediatr Obes 2009;4:28-35.

16. Page AS, Cooper AR, Griew $\mathrm{P}$, et al. Independent mobility in relation to weekday and weekend physical activity in children aged 10-11 years: the PEACH Project. Int J Behav Nutr Phys Act 2009;6:2.

17. Van Sluijs EM, Skidmore PM, Mwanza K, et al. Physical activity and dietary behaviour in a population-based sample of British 10-year old children: the SPEEDY study (Sport, Physical activity and Eating behaviour: environmental Determinants in Young people). BMC Public Health 2008;8:388.

18. Janz KF, Burns TL, Torner JC, et al. Physical activity and bone measures in young children: the lowa bone development study. Pediatrics 2001;107:1387-93.
19. Van Coevering P, Harnack L, Schmitz K, et al. Feasibility of using accelerometers to measure physical activity in young adolescents. Med Sci Sports Exerc 2005;37:867-71.

20. Mattocks C, Ness A, Leary S, et al. Use of accelerometers in a large field-based study of children: protocols, design issues, and effects on precision. J Phys Act Health 2008;5(Suppl 1):S98-111.

21. Sirard JR, Slater ME. Compliance with wearing physical activity accelerometers in high school students. J Phys Act Health 2009;6 (Suppl 1):S148-55.

22. Sirard JR, Kubik MY, Fulkerson JA, et al. Objectively measured physical activity in urban alternative high school students. Med Sci Sports Exerc 2008;40:2088-95.

23. Smith K, Joshi H. The Millennium Cohort Study. Popul Trends 2002;107:30-4.

24. Plewis I. Millennium Cohort Study: technical report on sampling. Chapter 11 (Weighting to adjust for non-response bias); ed. lan Plewis. 4th edn. London: Institute of Education, 2007:1-78.

25. Fairweather SC, Reilly J, Stanley G, et al. Using the Computer Science and Applications (CSA) activity monitor in preschool children. Pediatr Exerc Sci 2010;22:408-20.

26. Janz KF. Validation of the CSA accelerometer for assessing children's physical activity. Med Sci Sports Exerc 1994;26:369-75.

27. Trost SG, Way R, Okely AD. Predictive validity of three ActiGraph energy expenditure equations for children. Med Sci Sports Exerc 2006;38:380-7.

28. Plasqui G, Westerterp KR. Physical activity assessment with accelerometers: an evaluation against doubly labeled water. Obesity (Silver Spring) 2007:15:2371-9.

29. Baquet G, Stratton G, Van PE, et al. Improving physical activity assessment in prepubertal children with high-frequency accelerometry monitoring: a methodological issue. Prev Med 2007;44:143-7.

30. Geraci M. pawacc: Physical activity with accelerometers. R package version 1.00. 2012. http://r-forge.r-project.org/projects/pawacc/ (accessed July 2012)

31. R Core Development Team. R: a language and environment for statistical computing website [Internet]. Vienna(Austria): R Foundation for Statistical Computing; [cited July 2012]. http://www. R-project.org/ (accessed July 2012).

32. Rich C, Geraci M, Griffiths L, et al. Quality control methods in accelerometer data processing: identifying extreme counts. 2012 (under review)

33. Rich C, Geraci M, Griffiths L, et al. Quality control methods in accelerometer data processing: defining miniumum wear time. 2012. (under review)

34. Geraci M, Rich C, Sera F, et al. Technical report on accelerometry data processing in the Millennium Cohort Study. London: Institute of Child Health, University College London, 2012. http://discovery.ucl. ac.uk/1361699/ (accessed July 2012).

35. Plewis I. Non-Response in a Birth Cohort Study: the case of the Millennium Cohort Study. Int J Soc Res Methodol 2007;10:325-34.

36. Ketende SC. Millennium Cohort Study: technical report on response. 3rd edn. London: Institute of Education, University of London, 2010.

37. Noble M, Smith G, Penhale B. Measuring multiple deprivation at the small area level: the inidices of deprivation. London: Department of the Environment, Transport and the Regions, 2000.

38. Allison PD. Multiple regression: a primer. Thousand Oaks, CA: Pine Forge Press, 1999.

39. Van Sluijs EM, Fearne VA, Mattocks C, et al. The contribution of active travel to children's physical activity levels: cross-sectional results from the ALSPAC study. Prev Med 2009;48:519-24.

40. Wilkinson JD, Arheart KL, Lee DJ. Accuracy of parental reporting of secondhand smoke exposure: the National Health and Nutrition Examination Survey III. Nicotine Tob Res 2006;8:591-7.

41. Tate AR, Dezateux C, Cole TJ, et al. Factors affecting a mother's recall of her baby's birth weight. Int J Epidemiol 2005;34:688-95.

42. Walton S, Bedford H, Dezateux C. Use of personal child health records in the UK: findings from the millennium cohort study. BMJ 2006;332:269-70.

43. Wen LM, Van der Ploeg HP, Kite J, et al. A validation study of assessing physical activity and sedentary behavior in children aged 3 to 5 years. Pediatr Exerc Sci 2010;22:408-20.

44. Little RJA. Missing-data adjustments in large surveys. J Bus Econ Stat 1988;6:287-96. 